\begin{tabular}{ccc}
\hline AECORDS OF PHARMACEUTICAL \\
AND BIOMEDICAL SCIENCES
\end{tabular}

\title{
Chemical constituents and biological effects of Ganoderma mushroom
}

\author{
Neveen F. El-Sherif ${ }^{a}$, Safwat A. Ahmed ${ }^{b}$, Eman S. Habib $^{b}$, Reda F. A. Abdelhameed ${ }^{b}$ \\ ${ }^{a}$ Ministry of Health, ${ }^{b}$ Pharmacognosy Department, Faculty of Pharmacy, Suez Canal University, \\ Ismailia, Egypt.
}

Received on: 13. 11. 2019

Revised on: 13. 02. 2020

Accepted on: 07. 03. 2020

Correspondence Author:

Tel: +201092638387

E-mail address:

safwat_aa@yahoo.com

\begin{abstract}
Ganoderma is a medicinal mushroom that has been used for years for treatment of various diseases. Ganoderma mushroom was considered as "mushroom of immortality" in traditional Chinese medicine and was used to cure many diseases including cancer. Over the last 50 years, phytochemical studies led to isolation of more than 500 secondary metabolites from various Ganoderma species including lanostanes, triterpenes, meroterpenoids, sesquiterpenoids, hydroquinones, steroids, alkaloids and polysaccharides. In vitro and in vivo studies showed that Ganoderma mushrooms possess a wide range of biological activities, including anticancer, antihyperlipidemic, hypoglycemic, anti-inflammatory, antioxidant, antiplatelet aggregation, antiplasmodial, and antiviral activity. This review summarizes bioactive compounds isolated from different species of Ganoderma. The isolated compounds were tested for their anti-tumor in vitro activities in MCF-7 and MDA-MB-231 breast cancer cell lines. Ergosterol peroxide showed selective inhibition of MCF-7 (ER +ve) cell lines relative to MDA-MB-231 (ER -ve) cell lines with an $\mathrm{IC}_{50}$ of $12.9 \mu \mathrm{M}$ and $91 \mu \mathrm{M}$ respectively.
\end{abstract}

Keywords: Ganoderma, triterpenes, steroids, meroterpenoids, anticancer.

\section{Introduction}

Ganoderma is a genus of polypore mushrooms that belongs to the kingdom of fungi, division of Basidiomycota, family Polyporaceae (Ganodermataceae). It includes about 80 species, many of them from tropical regions (Richter et al., 2015). Ganoderma can be differentiated from other polypores because they have a double-walled basidiospore. They are popularly referred to as shelf mushrooms or bracket fungi (Kirk et al., 2008). Ganoderma is a wood degrading mushroom with hard fruiting body. It is not listed among edible mushrooms because its fruiting body is thick, corky and tough. Ganoderma is a medicinal mushroom that was used in Chinese traditional medicine for curing of chronic diseases like asthma, arthritis, bronchitis, nephritis, hypertension, insomnia, diabetes and cancer (Mizushina et al., 1998; Wasser and Weis, 1999).

Taxonomic studies of Ganoderma reported more than 300 species. Species of Ganoderma that were subjected to phytochemical investigation of their 
secondary metabolites and biological activities include Ganoderma lucidum, G. applanatum, $G$. colossum, G. sinense, G. cochlear, G. tsugae, G. amboinense, $G$. orbiforme, $G$. resinaceum, $G$. hainanense, G. concinna, G. pfeifferi, G. neojaponicum, G. australe, G. fornicatum, G. lipsiense, , G. boninense, G. capense and G. annulare.

\section{Chemical constituents of Ganoderma} mushrooms:

The main classes of biologically active compounds in different Ganoderma species are triterpenes, steroids and polysaccharides (Boh et al., 2007). In addition to these, lectins, nucleosides, and cerebrosides also play an important role as biologically active substances isolated from Ganoderma (Lu et al., 2004; Paterson, 2006).

\subsection{Triterpenoids}

Triterpenoids are the main secondary metabolites isolated from the methanol, ethanol and chloroform extracts of the spores, mycelia and fruiting bodies of Ganoderma mushroom (Lu et al., 2004; Lee et al., 2010). Triterpenes are composed of six isoprene units and they exist as acyclic, mono-, di-, tri-, tetraor pentacyclic carbon skeletons.
They occur in free form or as their ether, ester, or glycoside derivatives.

Free form triterpenoids include more than 200 compounds distributed in all species of Ganoderma. Ganoderic acids A-L were reported to be isolated from G. lucidum, G. sinense and $G$. amboinense (Nishitoba et al., 1987; Lin et al., 1993; El-Mekkawy et al.,1998; Qiao et al.,2007; Yang et al., 2012).

Applanoxidic acids A-H were isolated from different Ganoderma species; G. applanatum, $G$. annulare, G. australe (Chairul et al., 1991; León et al., 2003; Smania et al., 2003).

Triterpenoid derivatives include aldehyde derivatives such as lucialdehyde B, D, E that were isolated from G. lucidum (Ma et al., 2012). Alcoholic form triterpenes include mono-, di-, tri-, and tetra hydroxyl groups like ganoderiol A-J, ganodermanondiol , ganodermatriol, ganodermatetraol that were isolated from $G$. concinna, G. lucidum, G. sinense and $G$. hainanense (Arisawa et al.,1986; Gonzalez et al., 2002; Liu et al., 2012; Ma et al., 2013).

Table (1): Triterpenoid names, species (source) and literature listings from genus Ganoderma

\begin{tabular}{|c|c|c|c|}
\hline Number & Compound name & Species & Reference \\
\hline 1 & C30 lanostanes & (El-Mekkawy et al., \\
& & & G. lucidum \\
(Liu et al., 2012)
\end{tabular}


Rec. Pharm. Biomed. Sci. B: 4 (2), 25- 35, 2020

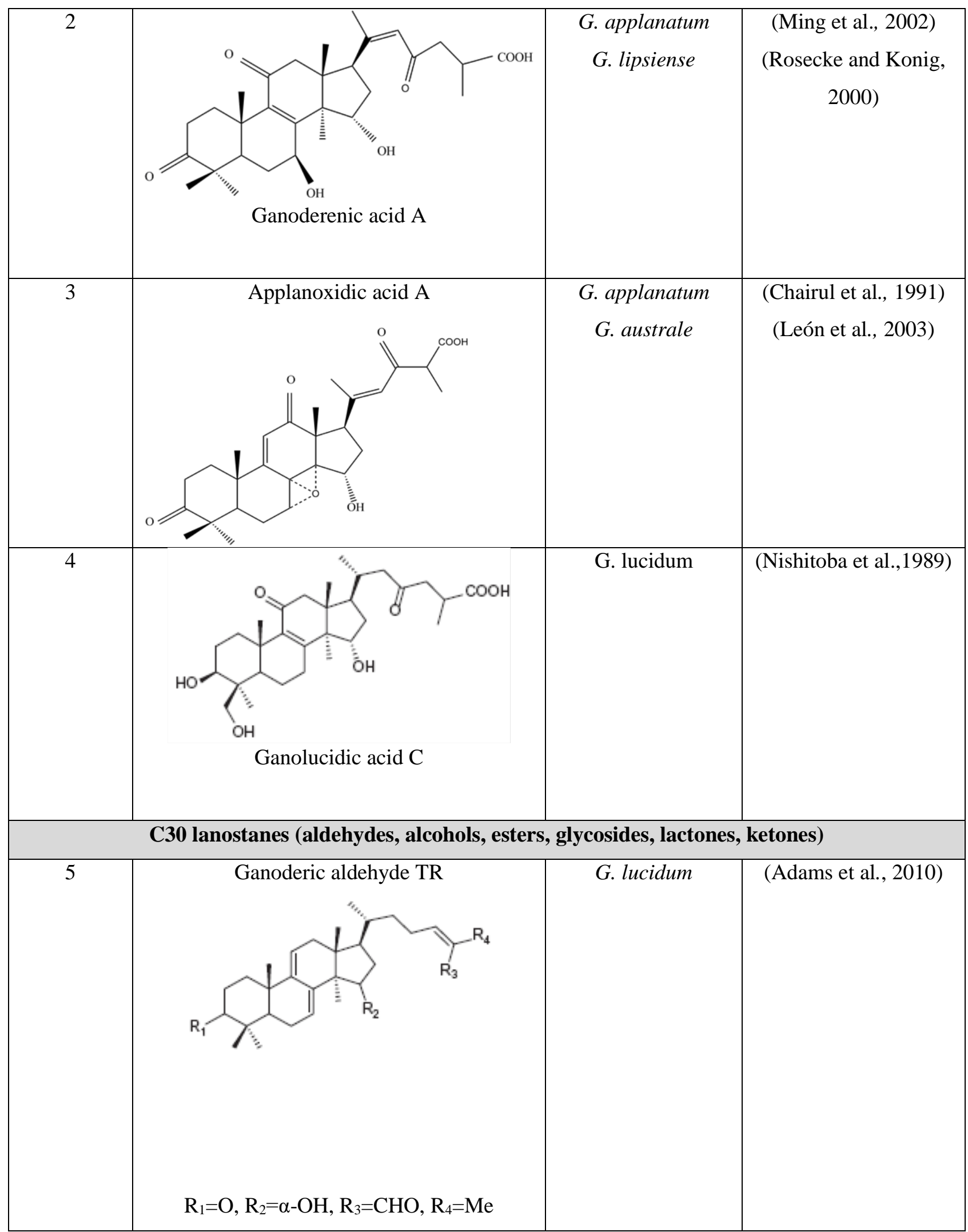




\begin{tabular}{|l|c|c|}
\hline & $\begin{array}{c}\text { G. lucidum, } \\
\text { G. concinna }\end{array}$ & $\begin{array}{c}\text { (Sato et al., 1986) } \\
\text { (Gonzalez et al.,2002) }\end{array}$ \\
(Fujita et al., 1986) \\
(Ma et al., 2013)
\end{tabular}

\subsection{Steroids}

Several steroids and steroidal esters were isolated from G. lucidum and other Ganoderma species. Major steroidal metabolites isolated from Ganoderma include ergosterol, ergosta-7,22-dien$3 \beta$-ol, ergosterol peroxide, ergosta-7,22-diene-3-one and ergosta-7,22-dien-3b-yl palmitate (Lin et al., 1993; Rosecke and Konig, 2000)

\subsection{Sesquiterpenoids}

Fushimi et al. isolated echinolactone D from the culture broth of $G$. applanatum (Fushimi et al., 2010). Later, Jung et al. isolated ganodermycin from fermentation of the basidiomycete $G$. applanatum (Jung et al.,2011).

\subsection{Meroterpenoids}

Peng et al. isolated four pairs of new polycyclic meroterpenoids enantiomers from $G$. cochlear,

from Ganoderma fornicatum fruiting bodies. Niu et al. isolated fornicin A, fornicin B and fornicin C from ethyl acetate extract by using normal phase silica gel (Niu et al., 2006).

\subsection{Alkaloids}

Liu et al. isolated four new alkaloids from the ethyl acetate extract of $G$. sinense fruiting bodies; sinensine B- E and one known alkaloid, sinensine (Liu et al.,2011). 
Rec. Pharm. Biomed. Sci. B: 4 (2), 25- 35, 2020

Table (2): Steroids names, species (source) and literature listings from genus Ganoderma

\begin{tabular}{|c|c|c|c|}
\hline Number & Compound name & Species & Reference \\
\hline 1 & $\overbrace{27}^{28}$ & $\begin{array}{l}\text { G. lipsiense } \\
\text { G. applanatum }\end{array}$ & $\begin{array}{l}\text { (Rosecke and Konig, } \\
\text { 2000) } \\
\text { (Ming et al., 2002) }\end{array}$ \\
\hline 2 & Ergosta-7,22-dien-3 $\beta$-ol & $\begin{array}{l}\text { G. amboinense } \\
\text { G. annulare }\end{array}$ & $\begin{array}{c}\text { Lin et al., } 1993 \\
\text { Smania et al., } 2003\end{array}$ \\
\hline 3 & Ergosterol peroxide & $\begin{array}{l}\text { G. lucidum } \\
\text { G. concinna }\end{array}$ & $\begin{array}{l}\text { Mizushina } \text { et al., } 1998 \\
\text { Gonzalez et al., } 2002\end{array}$ \\
\hline 4 & Ergosta-7,22-diene- $2 \beta, 3 \alpha, 9 \alpha$-triol & G. lucidum & Lin et al., 1993 \\
\hline
\end{tabular}


Table (3): Sesquiterpenoids names, species (source) and literature listings from genus Ganoderma

\begin{tabular}{|c|r|r|r|}
\hline Number & Compound name & Species & Reference \\
\hline 1 & Echinolactone D & G. applanatum & (Fushimi et al., 2010) \\
\hline $\mathbf{2}$ & & & \\
\hline
\end{tabular}

Table 4. Examples of meroterpenoids isolated from genus Ganoderma

\begin{tabular}{|c|c|c|c|}
\hline Number & Compound name & Species & Reference \\
\hline 1 & G. cochlear & (Peng et al.,2014) \\
\hline 2 & & & \\
\hline
\end{tabular}


Rec. Pharm. Biomed. Sci. B: 4 (2), 25- 35, 2020

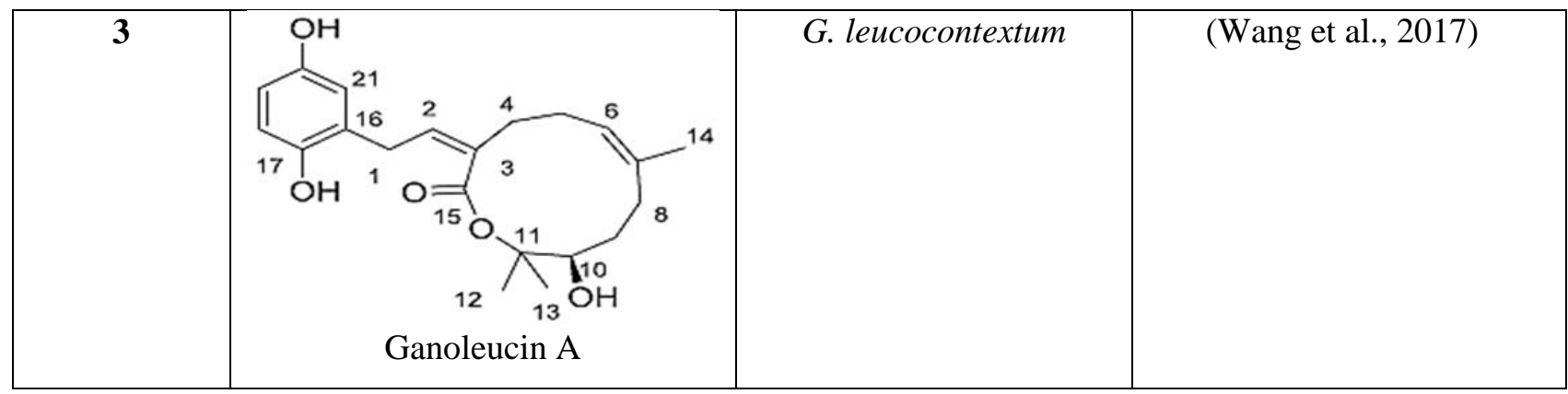

Table 5. Hydroquinones names, species (source) and literature listings from genus Ganoderma

\begin{tabular}{|c|c|c|c|}
\hline Number & Species & Reference \\
\hline 1 & G. colossum & (El Dine et al., 2009) \\
\hline 2 & G. colossum & (El Dine et al., 2009) \\
\hline 3 & & & \\
\hline
\end{tabular}

Table (6): Alkaloids names, species (source) and literature listings from genus Ganoderma

\begin{tabular}{|c|c|c|c|}
\hline Number & Compound name & Species & Reference \\
\hline 1 & Liu et al., 2011 & \\
\hline
\end{tabular}




\begin{tabular}{|l|l|l|}
\hline 2 & G. sinense & Liu et al., 2011 \\
\hline
\end{tabular}

Several ganocin A-C, possessing a spiro [ 4,5]decane ring system, along with ganocin $\mathrm{D}$ with an eight- membered ring (Peng et al.,2014).

In 2017, Wang et al. isolated new meroterpenoids (Ganoleucin A-C) from G. leucocontexum. Ethyl acetate extract was subjected to chromatographic separation using normal phase silica gel, sephadex LH20 and preparative HPLC (Wang et al., 2017).

\subsection{Hydroquinones}

El Dine et al. isolated two hydroquinones from Ganoderma colossum mushroom. Ganomycin B and Ganomycin I are farnesyl hydroquinones isolated from the chloroform extract of the fruiting bodies of Vietnamese mushroom (El Dine et al., 2009). Ganomycin B and I also fall into the group of meroterpenoids. New prenylated phenolic structures were isolated

\subsection{Polysaccharides}

Polysaccharides have been isolated from spores, mycelia and fruiting bodies of Ganoderma spp. More than 200 polysaccharides were isolated from various Ganoderma species (Huie and Di, 2004). The most frequent classes of polysaccharides isolated from Ganoderma spp. are glucans, glycoproteins, glycopeptides and water-soluble heteropolysaccharides with $1-3,1-4$, and $1-6 \alpha$ or $\beta$ bond between monomers (Lee et al., 1999).

\section{Biological activities of Ganoderma}

\subsection{Anticancer activity}

Kao et al. suggested that the anti-cancer activity of G. lucidum was due to its triterpenes and polysaccharides content eliminate tumor through several mechanisms. Triterpenes have five major mechanisms including cell cycle arrest, cytotoxicity, inhibition of metastasis of tumor cells, anti-inflammatory and antioxidant activity (Kao et al., 2013). Johnson and Lapadat reported that triterpenes were responsible for cell cycle arrest in human hepatocellular carcinoma $\mathrm{HuH}-7$ with no effect in normal liver cell lines. Excessive release of inflammatory cytokines chronically leads to carcinogenesis. On the other hand, polysaccharides improve immune system via stimulation of natural killer cells, cytotoxic T-lymphocytes and phagocytosis activity by macrophages and cytokines. G. lucidum also suppressed angiogenesis activity (Johnson and Lapadat, 2002).

\subsubsection{Breast cancer treatment}

Jiang et al. investigated the activity of G. lucidum fruiting bodies in inhibition of breast cancer. Three mechanisms were responsible for the beneficial effect of the whole powder extract; inhibition of serine threonine kinase /nuclear factor- $\mathrm{\kappa B}(\mathrm{Akt} / \mathrm{NF}$ $\kappa B)$, cell cycle arrest at G0/G1 and suppression of transcription of Cyclin D1 and cyclin-dependent protein kinase (cdk4) (Jiang et al., 2004).

\subsubsection{Stomach and colon cancer treatment}

Extracts of G. lucidum triggered the killing of human gastric carcinoma AGS cells through the activation of lanosteroids isolated from the fruiting bodies of $G$. resinaceum mushroom. In an in vitro model, ganoderesin, ganoderol $\mathrm{B}$ and lucidone A showed inhibitory effects against the increase of alanine aminotransferase (ALT) and aspartate aminotransferase (AST) levels in HepG2 cells induced by $\mathrm{H}_{2} \mathrm{O}_{2}$ compared to a control group in the range of their maximum non-toxic concentration (MNTC) (Peng et al., 2013).

the intrinsic apoptosis pathways by downregulating the anti-apoptotic $\mathrm{Bcl}-2$ protein and consequently elevating the $\mathrm{Bax} / \mathrm{Bcl}-2$ ratio. Moreover, G. lucidum extracts were shown to inactivate phosphatidylinositol-3 kinase (PI3K)/Akt of human gastric carcinoma AGS cells (Jang et al., 2010).

Ganodermanontriol, a purified triterpene from $G$. lucidum, was shown to inhibit the proliferation of HCT-116 and HT-29 colon cancer cells. In addition, Jedinak et al. demonstrated suppressed tumor growth in a xenograft model of these cells implanted in nude mice without any side effects (Jedinak et al., 2011). 


\subsubsection{Lung cancer treatment}

Lee et al. showed that ergosta-7,22-diene- $2 \beta, 3 \alpha, 9 \alpha-$ triol (EGDT) extracted from the fruiting bodies of G. lucidum mushroom, can activate apoptosis by DNA fragmentation and caspase-3 activation. In vivo, EGDT significantly decreased the Lewis lung carcinoma (LLC) growth, indicating that this triterpene fraction is one of the apoptotic parts of $G$. lucidum mushroom (Lee et al.,2011).

\subsection{Anti-human immunodeficiency virus (HIV)}

El Dine et al. investigated the activity of compounds isolated from G. colossum against HIV protease enzyme. G. colossum suppressed HIV-1 protease by a dual mechanism: inhibition of dimerization through interfacial region disruption by schisanlactone $\mathrm{A}$ triterpene and inhibition of active sites by ganomycin I and ganomycin B (EI Dine et al., 2009).

\subsection{Hepatoprotective activity}

Peng et al. investigated the hepatoprotective effect of lanosteroids isolated from the fruiting bodies of $G$. resinaceum mushroom. In an in vitro model, ganoderesin, ganoderol B and lucidone A showed inhibitory effects against the increase of alanine aminotransferase (ALT) and aspartate aminotransferase (AST) levels in HepG2 cells induced by $\mathrm{H}_{2} \mathrm{O}_{2}$ compared to a control group in the range of their maximum non-toxic concentration (MNTC) (Peng et al., 2013).

\subsection{Antiplatelet aggregation}

Jun and Ke-yan investigated the antiplatelet aggregation of the water extract of G. lucidum. In vitro, venous blood was drawn from 15 healthy volunteers to separate platelet poor plasma (PPP) then adding adenosine diphosphate (ADP) as platelet aggregation inducer with $3 \mu \mathrm{mol}$ resulting in significant inhibition of first and second phase of platelet aggregation. Oral administration of $1 \mathrm{gm}$ of G. lucidum extract 3 times daily for two weeks to 33 patients with atherosclerotic diseases, reduced weight and length of extracorporeal thrombi from $30 \mathrm{~mm}$ to $20.04 \mathrm{~mm}$ and from 103.9 to $85.2 \mathrm{~mm}$. Also, the platelet aggregation was inhibited after addition of ADP with $2 \mu \mathrm{mol}$ and $3 \mu \mathrm{mol}$ with $31.49 \%$ and $17.7 \%$ (Jun and Ke-yan, 1990).

\section{Conclusion}

Phytochemical studies led to the isolation of more than 500 active compounds from genus Ganoderma. The major compounds isolated were triterpenoids and steroids that showed in vitro and in-vivo anticancer activity towards different types of cancer especially hormonal dependent types such as breast cancer. Meroterpenoids and hydroquinones showed anti- HIV activity, hypoglycemic activity and anti-hyperlipidemic activity. Ganoderma mushrooms present a promising source of bioactive compound that deserve further investigation, especially the less investigated species.

\section{References}

Arisawa, M., Fujita, A., Saga, M., Fukumura, H., Hayashi, T., Shimizu, M., \& Morita, N., 1986. Three new lanostanoids from Ganoderma lucidum. Journal of natural products, 49, 621-625.

Boh, B., Berovic, M., Zhang, J., \& Zhi-Bin, L., 2007. Ganoderma lucidum and its pharmaceutically active compounds. Biotechnology annual review, 13, 265-301.

Chairul, Tokuyama, T., Hayashi, Y., Nishizawa, M., Tokuda, H., Chairul, S.M., Hayashi, Y., 1991. Applanoxidic acids A, B, C and D, biologically active tetracyclic triterpenes from Ganoderma applanatum. Phytochemistry, 30, 4105-4109.

Dou, M., Li, R. T. and Cheng, Y. X., 2016. Minor compounds from fungus Ganoderma cochlear. Chinese Herbal Medicines, 8, 85-88.

El Dine, R. S., El Halawany, A. M., Ma, C. M. and Hattori, M., 2009. Inhibition of the dimerization and active site of HIV-1 protease by secondary metabolites from the Vietnamese mushroom Ganoderma colossum. Journal of natural products, 72, 2019-2023

El-Mekkawy, S., Meselhy, M. R., Nakamura, N., Tezuka, Y., Hattori, M., Kakiuchi, N., ... \& Otake, T., 1998. Anti-HIV-1 and anti-HIV-1-protease substances from Ganoderma lucidum. Phytochemistry, 49, 1651-1657.

Fujita, A., Arisawa, M., Saga, M., Hayashi, T., \& Morita, N., 1986. Two new lanostanoids from Ganoderma lucidum. Journal of Natural Products, 49(6), 1122-1125. 
Fushimi, K., Horikawa, M., Suzuki, K., Sekiya, A., Kanno, S., Shimura, S., \& Kawagishi, H., 2010. Applanatines A-E from the culture broth of Ganoderma applanatum. Tetrahedron, 66(48), 9332-9335.

Gao, J. J., Min, B. S., Ahn, E. M., Nakamura, N., Lee, H. K., \& Hattori, M., 2002. New triterpene aldehydes, lucialdehydes A-C, from Ganoderma lucidum and their cytotoxicity against murine and human tumor cells. Chemical and Pharmaceutical Bulletin, 50, 837-840.

González, A. G., León, F., Rivera, A., Padrón, J. I., González-Plata, J., Zuluaga, J. C., ... \& Bermejo, J. (2002). New Lanostanoids from the Fungus Ganoderma c oncinna. Journal of natural products, 65(3), 417-421.

Huie, C. W., \& Di, X., 2004. Chromatographic and electrophoretic methods for Lingzhi pharmacologically active components. Journal of Chromatography B, 812, 241-257.

Jang, K. J., Han, M. H., Lee, B. H., Kim, B. W., Kim, C. H., Yoon, H. M., \& Choi, Y. H., 2010. Induction of apoptosis by ethanol extracts of Ganoderma lucidum in human gastric carcinoma cells. Journal of acupuncture and meridian studies, 3, 24-31

Jedinak, A., Thyagarajan-Sahu, A., Jiang, J., \& Sliva, D., 2011. Ganodermanontriol, a lanostanoid triterpene from Ganoderma lucidum, suppresses growth of colon cancer cells through ss-catenin signaling. International journal of oncology, 38, 761-767.

Jiang, J., Slivova, V., Harvey, K., Valachovicova, T. and Sliva, D., 2004. Ganoderma lucidum suppresses growth of breast cancer cells through the inhibition of Akt/NF- $\mathrm{kB}$ signaling. Nutrition and cancer 49, 209-216

Johnson, G. L. and Lapadat, R., 2002. Mitogenactivated protein kinase pathways mediated by ERK, JNK, and p38 protein kinases. Science, 298, 1911-1912

Jun, T. and Ke-yan, F., 1990. Experimental and clinical studies on inhibitory effect of Ganoderma lucidum on platelet aggregation. Journal of Tongji Medical University, 10, 240-243.
Jung, M., Liermann, J. C., Opatz, T., \& Erkel, G., 2011. Ganodermycin, a novel inhibitor of CXCL10 expression from Ganoderma applanatum. The Journal of antibiotics, 64, 683

Kao, C., Jesuthasan, A. C., Bishop, K. S., Glucina, M. P. and Ferguson, L. R., 2013. Anti-cancer activities of Ganoderma lucidum: active ingredients and pathways. Functional Foods in Health and Disease, 3, 48-65.

Kirk, P.M., Cannon, P.F., Minter, D.W. and Stalpers, J.A., 2008. Dictionary of the Fungi (10th Ed.). Wallingford, England, Cabi.

Lee, K. M., Lee, S. Y., \& Lee, H. Y., 1999. Bistage control of $\mathrm{pH}$ for improving exopolysaccharide production from mycelia of Ganoderma lucidum in an air-lift fermentor. Journal of bioscience and bioengineering, 88(6), 646-650.

Lee, I., Kim, H., Youn, U., Kim, J., Min, B., Jung, H., ... \& Bae, K., 2010. Effect of lanostane triterpenes from the fruiting bodies of Ganoderma lucidum on adipocyte differentiation in 3T3-L1 cells. Planta medica, 76, 1558-1563.

Lee, M. K., Hung, T. M., Cuong, T. D., Na, M., Kim, J. C., Kim, E. J., ... \& Hattori, M., 2011. Ergosta-7, 22-diene-2 $\beta, 3 \alpha, 9 \alpha$-triol from the Fruit Bodies of Ganoderma lucidum Induces Apoptosis in Human Myelocytic HL-60 Cells. Phytotherapy research, 25, 1579-1585.

Leon, F., Valencia, M., Rivera, A., Nieto, I., Quintana, J., Estevez, F., \& Bermejo, J. 2003. Novel cytostatic lanostanoid triterpenes from Ganoderma australe. Helvetica Chimica Acta, 86(9), 3088-3095

Lin, C.N., Kuo, S.H., Won, S.J., 1993. Steroids of formosan Ganoderma amboinense. Phytochemistry, 32, 1549-1551.

Liu, J. Q., Wang, C. F., Peng, X. R., \& Qiu, M. H., 2011. New alkaloids from the fruiting bodies of Ganoderma sinense. Natural products and bioprospecting, 1, 93-96.

Liu, J. Q., Wang, C. F., Li, Y., Luo, H. R., \& Qiu, M. H., 2012. Isolation and bioactivity evaluation of terpenoids from the medicinal fungus Ganoderma sinense. Planta medica, 78(04), 368-376. 
Lu, Q. Y., Jin, Y. S., Zhang, Q., Zhang, Z., Heber, D., Go, V. L. W., ... \& Rao, J. Y., 2004. Ganoderma lucidum extracts inhibit growth and induce actin polymerization in bladder cancer cells in vitro. Cancer letters, 216, 9-20.

Ma, B. J., Zhou, Y., Ruan, Y., Ma, J. C., Ren, W., \& Wen, C. N., 2012. Lanostane-type triterpenes from the sporoderm-broken spores of Ganoderma lucidum. The Journal of antibiotics, 65, 165.

Ma, Q. Y., Luo, Y., Huang, S. Z., Guo, Z. K., Dai, H. F., \& Zhao, Y. X., 2013. Lanostane triterpenoids with cytotoxic activities from the fruiting bodies of Ganoderma hainanense. Journal of Asian natural products research, 15, 1214-1219.

Ming, D., Chilton, J., Fogarty, F., \& Towers, G. N., 2002. Chemical constituents of Ganoderma applanatum of British Columbia forests. Fitoterapia, 73, 147-152.

Mizushina, Y., Hanashima, L., Yamaguchi, T., Takemura, M., Sugawara, F., Saneyoshi, M., ... \& Sakaguchi, K., 1998. A mushroom fruiting bodyinducing substance inhibits activities of replicative DNA polymerases. Biochemical and biophysical research communications, 249, 17-22.

Nishitoba, T., Sato, H., \& Sakamura, S., 1987. Novel mycelial components, ganoderic acid $\mathrm{Mg}$, $\mathrm{Mh}, \mathrm{Mi}, \mathrm{Mj}$ and $\mathrm{Mk}$, from the fungus Ganoderma lucidum. Agricultural and biological chemistry, 51(4), 1149-1153.

Nishitoba, T., Goto, S., Sato, H., \& Sakamura, S., 1989. Bitter triterpenoids from the fungus Ganoderma applanatum. Phytochemistry, 28, 193197.

Niu, X. M., Li, S. H., Sun, H. D. and Che, C. T., 2006. Prenylated Phenolics from Ganoderma fornicatum. Journal of natural products 69, 13641365.

Paterson, R. R. M. 2006. Ganoderma-a therapeutic fungal biofactory. Phytochemistry, 67, 1985-2001.

Peng, X. R., Liu, J. Q., Han, Z. H., Yuan, X. X., Luo, H. R., \& Qiu, M. H., 2013. Protective effects of triterpenoids from Ganoderma resinaceum on H2O2-induced toxicity in HepG2 cells. Food chemistry, 141, 920-926.
Peng, X. R., Liu, J. Q., Wan, L. S., Li, X. N., Yan, Y. X., \& Qiu, M. H., 2014. Four new polycyclic meroterpenoids from Ganoderma cochlear. Organic letters, 16, 5262-5265

Richter, C., Wittstein, K., Kirk, P. M., \& Stadler, M., 2015. An assessment of the taxonomy and chemotaxonomy of Ganoderma. Fungal Diversity, 71, 1-15.

Rios, J. L., Andujar, I., Recio, M. C., \& Giner, R. M., 2012. Lanostanoids from fungi: a group of potential anticancer compounds. Journal of natural products, 75, 2016-2044.

Rösecke, J., \& König, W. A., 2000. Constituents of various wood-rotting basidiomycetes. Phytochemistry, 54, 603-610.

Sato, H., Nishitoba, T., Shirasu, S., Oda, K., \& Sakamura, S., 1986. Ganoderiol A and B, new triterpenoids from the fungus Ganoderma lucidum (Reishi). Agricultural and biological chemistry, 50, 2887-2890.

Smania, E. F. A., Delle Monache, F., Smania Jr, A., Yunes, R. A., \& Cuneo, R. S., 2003. Antifungal activity of sterols and triterpenes isolated from Ganoderma annulare. Fitoterapia, 74, 375-377.

Wang, K., Bao, L., Ma, K., Zhang, J., Chen, B., Han, J. and Liu, H., 2017. A novel class of $\alpha$ glucosidase and HMG-CoA reductase inhibitors from Ganoderma leucocontextum and the antidiabetic properties of ganomycin I in KK-Ay mice. European journal of medicinal chemistry, 127, 1035-1046

Wasser, S. P., \& Weis, A. L., 1999. Therapeutic effects of substances occurring in higher Basidiomycetes mushrooms: a modern perspective. Critical Reviews ${ }^{\mathrm{TM}}$ in Immunology, 19, $1-12$.

Yang, S. X., Yu, Z. C., Lu, Q. Q., Shi, W. Q., Laatsch, H., \& Gao, J. M., 2012. Toxic lanostane triterpenes from the basidiomycete Ganoderma amboinense. Phytochemistry letters, 5, 576-580. 